CBIE-LACLO 2015

Anais do XXI Workshop de Informática na Escola (WIE 2015)

\title{
Contribuições do dialogismo na interação didática assíncrona em mídia social na internet
}

\author{
Sílvia Cristina Dotta ${ }^{1}$, Elaine Alves Testoni ${ }^{2}$ \\ ${ }^{1}$ Centro de Matemática, Computação e Cognição - Universidade Federal do ABC (UFABC) \\ Avenida dos Estados, 5001 - CEP 09210-580 - Santo André - SP - Brazil \\ ${ }^{2}$ Programa de Pós-Graduação em Ciências Humanas e Sociais - Universidade Federal do \\ ABC (UFABC) Avenida dos Estados, 5001 - CEP 09210-580 - Santo André - SP - Brazil \\ silvia.dotta@ufabc.edu.br, elaine.testoni@ufabc.edu.br
}

\begin{abstract}
This paper aims to investigate the contribution of the dialogism and enunciative demonstrations in asynchronous interaction in social media on the internet. The object of analysis corresponds to a systematic didactic activity on Facebook, as a resource to motivate undergraduate research interests that promote academic interaction outside the university space. In this sense, we analyze the interactive and dialogic approaches between students through practical experience, in which the teacher proposes to students a debate about a particular movie. The expected results indicate the dialogism as a relevant way to the seizure of cognitive senses and to promote learning.
\end{abstract}

Resumo. O objetivo deste artigo é investigar a contribuição do dialogismo e das manifestações enunciativas na interação assíncrona em mídia social na internet. Para isso, o objeto de análise corresponde a uma atividade didática sistematizada no Facebook, como recurso para estimular graduandos a interesses de pesquisa que promovam a interação acadêmica fora do espaço universitário. Nesse sentido, serão analisadas as abordagens interativas e dialógicas entre os interlocutores por meio da experiência prática, na qual a docente propõe aos alunos um debate acerca de dado filme. Os resultados esperados assinalam o dialogismo como meio relevante para a apreensão de sentidos cognitivos e para a promoção da aprendizagem.

\section{Introdução}

As mídias sociais abrangem estruturas socialmente construídas, formadas pela comunicação mediada por computador e pelo resultado dessa mediação na correspondência dos fluxos de informação e de interações sociais [Recuero, 2009]. A apropriação de um grupo em rede social demanda o compartilhamento cognitivo das ferramentas disponíveis e a atividade colaborativa dos atores em relação às informações difundidas com propósitos comuns. Para tanto, a interação proveniente desse espaço abrange dinâmicas informacionais que podem ser utilizadas para fomentar ações didáticas entre os participantes do discurso.

As atividades colaborativas propiciam atitudes de negociação no ambiente interacional cuja interatividade no ensino compreende práxis coordenadas e sincronizadas. 
CBIE-LACLO 2015

Anais do XXI Workshop de Informática na Escola (WIE 2015)

Tais práxis colocam o docente como protagonista na elaboração de métodos capazes de regulamentar estruturas que fecundem o processo colaborativo. Estas estruturas podem ser oriundas do desempenho do professor voltado para o planejamento e orientação das atividades didáticas assim como podem decorrer do cenário no qual a ação pedagógica se insere. [Dotta, 2011].

Os efeitos enunciativos e a articulação do discurso são relevantes para estabelecer as relações socialmente construídas e, quando essas relações se voltam a interesses educacionais a partir de mídia social, acreditamos que o dialogismo se instaura como recurso necessário para a promoção de sentidos no que tange à aprendizagem colaborativa. Por conseguinte, essas abordagens são ancoradas nos estudos dialógicos propostos por Bakhtin (2009), nos quais o dialogismo é descrito como condição do sentido discursivo. Para ele, os elementos enunciativos contam com traços da linguagem apresentados na relação entre os atores e estão associados à participação dos sujeitos e dos discursos que os antecedem. Logo, há uma compreensão responsiva e ativa que redige o princípio do diálogo num jogo de alteridade, apreensão de significados e de sentidos, na qual o sentido do texto e a significação das palavras são assentados na produção e interpretação contextual e dependem da interação entre os sujeitos.

Dessa maneira, justificamos a escolha do tema pelo interesse em demonstrar as redes sociais não apenas como espaço de interação sociocultural, mas como importante cenário para fins didático-pedagógicos, encontrando na aprendizagem dialógica caminhos promissores para a construção dos saberes significativos. Por essa razão, o objetivo deste trabalho é analisar a relevância do dialogismo e dos elementos enunciativos do discurso, na interação didática assíncrona, em mídia social na internet.

O problema compreende os elementos necessários para a constituição dialógica da linguagem que possam consolidar as produções de sentido expressas na interação assíncrona mediatizada. Instaura-se, portanto, a indagação relativa à análise: como o dialogismo e as concepções enunciativas contribuem para a promoção de sentido em atividades voltadas ao ensino-aprendizagem em mídia social na internet?

A hipótese é que o dialogismo e os elementos enunciativos do discurso expressos nas propostas didáticas, em mídia social, contribuem para a difusão dos efeitos de sentidos que se apresentam nas ações reflexivas, críticas, intencionais, desafiadoras e persuasivas registradas na alteridade colaborativa dos interlocutores.

As premissas metodológicas incluem a pesquisa exploratória, tendo como objeto de investigação uma atividade didática publicada no Facebook a fim de estimular interesses acadêmicos fora do espaço universitário. Pressupõem ainda análises teóricas firmadas, entre outras possibilidades, nos estudos desenvolvidos por Bakhtin (2009, 2011), Freire (1987), Dotta (2011) e Recuero (2009), conforme veremos na sessão de Metodologia.

Os propósitos que trataremos neste artigo permeiam os desdobramentos do dialogismo observados nas interações assíncronas e nos resultados provenientes de tais desdobramentos para a apreensão de significados e para a verificação dos efeitos de sentido provenientes das relações dinâmicas. 
CBIE-LACLO 2015

Anais do XXI Workshop de Informática na Escola (WIE 2015)

\section{Estruturas dialógicas: interação e mídia social}

As interações resultantes do contexto didático assumem foco expressivo em atividades não presenciais difundidas na internet em função do caráter discursivo-enunciativo que configura as projeções da linguagem, suas particularidades comunicacionais e as abordagens relativas à tecnologia e às noções sociais que possam intervir na comunicação [Dotta e Giordan, 2006].

Na interação assíncrona, a perspectiva de resposta não ocorre de forma imediata no tempo da interação. Os atores compartilham dados com um ou mais participantes em momentos oportunos distintos e dessa forma, é possível retomar conteúdos explorados, resgatar discussões inconclusas e verificar os perfis interativos por meio de convergências, opiniões, percepções, divergências e posturas diversas nos encadeamentos da linguagem que dão suporte para uma progressão continuada de informações [Dotta, 2009].

A atuação enunciativa de um integrante depende da assimilação de conteúdo a partir da relação com o outro e, para que a comunicação imprima significado, o envolvimento e a satisfação mútua entre as partes são de grande relevância. Decorrem desse comportamento as ações de natureza atitudinal ou linguística, responsáveis pela reação do ouvinte no consentimento ou não das concepções enunciativas, na confirmação ou antecipação de respostas para o locutor, na relação com outros enunciados.

Pensando nisso, recorremos à composição enunciativa disposta na interação verbal apresentada por Bakhtin (2009), a fim de nos revelar os papéis assumidos pelos atores nas trocas discursivas. Estes atores são caracterizados ora como eu e ora como $t u$. O eu representa o emissor e o $t u$ assume o caráter de receptor, posturas estas que concebem aos participantes, perfis interativos, independentemente do nível de atuação que é concedido às partes envolvidas.

De acordo com Dotta e Giordan (2014, p. 78), a interação no ambiente virtual é resultado da composição de um sistema de comunicação. "Isso significa que no papel de emissor, espera-se a participação do receptor, no sentido de que esse possa (deva) interferir na mensagem, articulando inúmeras possibilidades de significações, desconstruções e reconstruções".

Por esse ângulo, levamos os interlocutores a exprimir suas ideias a partir de diferentes linguagens que estimulam a interação verbal partindo de expressões textuais, troca de experiências, dinamismo e reflexões em contextos problematizadores e dialógicos [Freire, 1987], os quais não se restringem à tecnologia, mas ao exercício de ação e transformação dos atores sociais.

As ações problematizadoras pressupõem diálogos. O diálogo, no conceito de Bakhtin (2011), consiste na disposição de abordagens enunciativas do discurso que se mescla a outras disposições discursivas em conexão com o discurso alheio. Desse modo, o fazer dialógico supera o poder da palavra, fomenta ações e reflexões, distancia-se do exercício comedido da troca de ideias e aproxima-se do pensamento crítico. Por isso, passa a ser um dos propósitos mais significativos da interação verbal. A dialogicidade, nessa perspectiva, assume caráter significante no momento em que instiga a conduta criativa e a 
CBIE-LACLO 2015

Anais do XXI Workshop de Informática na Escola (WIE 2015)

transformação do saber [Freire, 1987]. Para que essa transformação ocorra em ofertas didáticas, precisamos inquietar os atores discursivos no que diz respeito as suas posturas sociais e as suas percepções na relação com os outros atores.

Nessa lógica, entendemos que as mídias sociais no espaço não presencial mediado pela internet representam palco propenso para subsidiar interesses de educação em ações de ensino-aprendizagem, uma vez que a correspondência dialógica encontra cenário fecundo entre os atores sociais a partir de atitudes de interesse comum. De acordo com Dotta (2011, p. 610), "as mídias sociais (MS) podem ser conceituadas como espaços de colaboração, de compartilhamento de informações, de construção coletiva de conhecimento".

Por esse motivo, a escolha do Facebook como mídia social capaz de englobar os interesses educacionais não foi aleatória, visto que abriga e organiza um sistema de perfis e de comunidades. "O sistema é muitas vezes percebido como mais privado que outros sites de redes sociais, pois apenas usuários que fazem parte da mesma rede podem ver o perfil uns dos outros" [Recuero, 2009, p. 170]. Diante disso, percebemos que os recursos disponíveis no Facebook suscitam um ambiente valorativo de conveniência pedagógica possibilitando um processo colaborativo e dialógico de apreensão cognitiva.

\section{Metodologia}

O instrumento de averiguação, objeto desta análise, diz respeito a uma atividade didática sistematizada no Facebook, proposta pela disciplina Projeto Dirigido e direcionada a alunos de graduação da Universidade Federal do ABC, no ano de 2014. A disciplina objetiva formar os alunos para a elaboração de projetos de pesquisa científica. A atividade didática conduzida na mídia social tem como finalidade propiciar interação acadêmica fora do espaço universitário, levar os alunos a refletirem sobre as inúmeras possibilidades metodológicas para a condução de uma pesquisa e a importância de seguir o método científico para se atingir objetivos de pesquisa.

A atividade corresponde a um debate estimulado a partir dos interesses de pesquisa provenientes do contexto disciplinar, sobre o filme "Memento" (título original), gênero drama/suspense, dirigido por Christopher Nolan (2000). O filme conta a história de um jovem rapaz que tem a esposa assassinada de modo violento e sai em busca do possível criminoso. Todavia, o impacto brutal da tragédia deixa uma sequela: ele perde a memória de curto prazo - fato que o leva a guardar informações apenas por pequenos espaços de tempo. Para conseguir manter-se conectado às circunstâncias do presente a fim de descobrir o assassino, o protagonista desenvolve uma metodologia de fazer fotos instantâneas, anotar informações nessas fotos e tatuar no próprio corpo informações essenciais para seus objetivos.

A estrutura da atividade consolida um debate que permite a polêmica clara decorrente do confronto dialógico em que as posições dos interlocutores se mostram pelas argumentações persuasivas dos prós ou dos contra acerca das circunstâncias a serem discutidas. Para tanto, a mediação se nutre do apoio da docente responsável por apresentar a finalidade do estudo, evidenciar a focalização do assunto, explanar os procedimentos de 
pesquisa, designar o prazo de postagem e sugerir correlações dinâmicas instituídas de apreciações cabíveis e significativas.

Dessa forma, a docente (D) apresenta as instruções necessárias para o desenvolvimento da atividade. Em seguida, os estudantes (E) se organizam em torno das apreciações relativas ao texto e sistematizam a dinâmica a partir de exposições reflexivas, réplicas e tréplicas oriundas do propósito contextual. Delineada a apresentação da estrutura que organiza o debate, o quadro 1 explicita as orientações da docente para a atividade.

\section{Quadro 1. Orientações da docente para a atividade}

\section{D - 27 mar. 2014, às 10h57}

Esta atividade deve ser realizada até às $23 \mathrm{~h}$ do dia 13/04.

\section{Assistir ao filme "Memento" [Christopher Nolan, 2000].}

Ao assistir ao filme "Memento", procure identificar:

Objetivo (de pesquisa) do protagonista.

Problema da pesquisa, hipótese, justificativa, contextualização.

Referenciais (teóricos) utilizados pelo protagonista para analisar seus achados.

Metodologia (de pesquisa) adotada pelo protagonista para realizar sua pesquisa.

Participar de discussões do grupo do Facebook.

1. Primeiro POST: Reflita e procure responder.

Qual sua opinião sobre o filme?

Procure explicitar o objetivo, problema, hipótese, referenciais etc. Em seguida faça uma reflexão: o protagonista atingiu seu objetivo de pesquisa? Corroborou suas hipóteses? Os referenciais foram adequados para a realização da pesquisa? Os métodos foram adequados e/ou suficientes para a conclusão da pesquisa?

2. RÉPLICA: Em seguida, localize ao menos uma participação de um colega cujas ideias sejam contrárias às suas (com quem você discorde) e argumente explicitando os pontos da discordância e sua justificativa.

3. TRÉPLICA: Selecione ao menos um comentário de seus colegas a respeito de sua opinião inicial e contraargumente, ou reconstrua seus argumentos iniciais.

A fim de preservar a identidade dos estudantes, os quatro componentes de um determinado grupo, escolhidos para compor esta análise, serão identificados pela numeração equivalente de 1 a 4, sendo reconhecidos pelas abreviações descritas como E1, E2, E3 e E4.

\section{Análise das interações em atividade didática no Facebook: dialogismo e produção de sentido}

A relação comunicacional derivada da atividade didática em estudo permeia os desdobramentos dialógicos e as produções de sentido a serem observadas na interação assíncrona e problematizadora.

A ação do docente constrói uma circunstância problematizadora, na qual os estudantes se sentem desafiados na relação para e com o meio. Os desafios potencializam o desejo de superar obstáculos e buscar caminhos possíveis para resolvê-los. À vista disso, passam a perceber a totalidade que contempla o enredo e não se limitam a uma resposta estanque, ao contrário, promovem uma observação crítica dos fatos e por meio delas, instauram novos desafios. Assim, "a educação problematizadora afirma a dialogicidade e se faz dialógica" [Freire, 1987, p. 42]. 
CBIE-LACLO 2015

Anais do XXI Workshop de Informática na Escola (WIE 2015)

$\mathrm{Na}$ interação dialógica o eu configurado na enunciação do mediador automaticamente projeta um $t u$ e, numa cadência simultânea de participações organizadas dos sujeitos, novas atribuições de outros $e u$ e $t u$ vão surgindo.

Os contextos expressos no quadro 2 demonstram apontamentos que são compartilhados por meio de um processo de ação dinâmica, verificado na interação assíncrona entre os interlocutores.

\section{Quadro 2. Interação do estudante - E1}

\section{E1 - 06 abr. 2014, às 19h20}

O problema é que Leonard possuía amnésia, e desta forma não conseguia memorizar nenhum fato depois do dia do assassinato. Assim, ele tatuava todos os fatos importantes para prosseguir com sua investigação. Além disso, ele fotografava lugares e pessoas importantes que ele deveria se lembrar.

Na realidade, Leonard nunca irá alcançar seu real objetivo, pois a amnésia sempre fará com que ele se esqueça dos fatos recentes, das informações descobertas e quem são as pessoas realmente confiáveis. Seus referenciais e métodos foram inadequados, fotos e pessoas poderiam acabar induzindo-o a acreditar em algo que não ocorreu. Natalie, por exemplo, se aproveitou de sua amnésia e o fez acreditar que seu noivo era o procurado "John G.". Quanto às hipóteses, ele as seguiu até o final, e isso ficou evidente quando Leonard anotou a placa do carro de Doddy, e passou novamente a acreditar que ele era o tal "John G."

No quadro 2, E1 respeita a proposta enunciativa e defende uma posição que gera um outro desdobramento, conforme mostra o quadro 3.

\section{Quadro 3. Interação do estudante - E2}

\section{E2 - 11 abr. 2014, às $22 \mathrm{~h} 05$}

não tive a mesma visão de alguns fatos do filme como você. Porém concordo com sua conclusão de que Leonard nunca irá alcançar seu real objetivo e que seus métodos não foram adequados. Ficou bem evidente no filme a manipulação que as pessoas conseguiam fazer na vida de Leonard, através do exemplo que você citou da Natalie (usando Leonard para se vingar do traficante que ela acredita ter matado seu noivo) e no exemplo que citei em meu post sobre a forma com que Toddy usava Leonard. As tatuagens e as informações nas fotos eram conclusões momentâneas que Leonard tinha e muitas vezes ele não conseguia unir as informações para entender o que realmente estava acontecendo.

Os efeitos da constituição do enunciado promovem nova observação, descrita no quadro 4.

\section{Quadro 4. Interação do estudante - E1}

\section{E1- 11 abr. 2014, às 22h12}

Na verdade, esses "fatos importantes" são na perspectiva de Leonard. De qualquer forma, ele até tentava procurar fontes que pudessem ser mais confiáveis, como a cópia da investigação que a polícia fez na época da morte de sua esposa. Porém, isso não garante a veracidade desses papéis, pois, como foi dito, eles poderiam ser alterados a qualquer momento.

\section{O quadro 5 destaca o consentimento de E2 sobre a observação de E1.}

\section{Quadro 5. Interação do estudante - E2}

\section{E2 - 11 abr. 2014, às 22h15}

Concordo. Nenhum fato era totalmente confiável, deixando até na dúvida se algumas evidências não teriam sido alteradas pelo próprio Leonard. 
Com base nas considerações de E1 e E2 é possível notar a focalização dos acontecimentos por meio de uma concordância parcial. E2 apresenta uma postura contraditória sobre determinados valores, mas reitera a pontuação de E1 a respeito do objetivo e dos métodos conferidos à personagem protagonista. Assim sendo, as relações dialógicas são estabelecidas na interação entre o $e u$ e o $t u$, que assumem novos papéis na enunciação.

No revezamento entre os sujeitos do discurso encenados por E1 e E2 surge uma forma autêntica de comunicação discursiva que, de acordo com as concepções bakhtinianas, intitula-se réplica. Ora E1 é representado por $e u$ e E2 por $t u$, ora tais posições são invertidas. Cada réplica, independentemente do grau de formalidade, de expressão, ou de conteúdo, admite uma conclusibilidade peculiar relativa ao posicionamento do falante, que produz uma resposta da qual se espera um posicionamento responsivo. [Bakhtin, 2011]. "A conclusibilidade do enunciado é uma espécie de aspecto interno da alternância dos sujeitos do discurso; essa alternância pode ocorrer precisamente porque o falante disse (ou escreveu) tudo o que quis dizer em dado momento ou sob dadas condições" [Bakhtin, 2011, p. 280]. Logo, a conclusibilidade se reveste no discurso de consentimento ou refutação esboçando diferentes significados.

O dialogismo pressupõe sentido enunciativo. Para estabelecer sentido, o enunciado é composto a partir de outro enunciado e abriga diferentes vozes que, independentemente de se manifestarem ou não, englobam a esfera do discurso. A relação entre enunciados sempre vai apontar uma característica heterogênea pelo fato de haver versatilidade de posições [Bakhtin, 2009].

Pensando nisso, ao término desta primeira situação do debate, E2 corrobora o ponto de vista frisado por E1 quando destaca a concordância sobre as possíveis alterações das evidências encontradas por Leonard, o protagonista do filme e objeto da atividade. A referida ação demonstra que o enunciado é uma condição admitida por um enunciador, portanto é promotor de sentido.

Outro olhar pode ser notado na interpretação do recorte textual exibido no quadro 6.

\section{Quadro 6. Interação do estudante - E3}

\section{E3 - 09 abr. 2014, às $11 \mathrm{~h} 13$}

O objetivo de Leonard era esconder o seu verdadeiro eu, partindo da hipótese de que Tood é sua consciência (mostra o tempo todo o que Leonard realmente é).

O grande problema da trama é que Leonard precisava arranjar um meio de não acreditar em suas próprias mentiras, pois ele sempre achava um motivo para tudo.

Leonard usa como referencia uma espécie de linguagem corporal, onde enfatiza sempre que a memoria não é totalmente confiável. Sua metodologia principal é fazer de sua rotina um habito, também fixando lembranças em objetos palpáveis, como suas fotos.

O protagonista conseguiu esconder de todo o seu verdadeiro caráter, se mostrando sempre uma pessoa sensível e indefesa, corroborando com a hipótese de que Todd na verdade é sua consciência.

Suas referencias foram essenciais para o cumprimento de sua proposta, pois legitimavam as realidades que ele mesmo criava, assim, o método da rotina que ele usava era adequado.

A participação de mais um ator destaca nova consideração sobre a trama, como demonstra o quadro 7. 
CBIE-LACLO 2015

Anais do XXI Workshop de Informática na Escola (WIE 2015)

\section{Quadro 7. Interação do estudante - E2}

\section{E2 - 11 abr. 2014, às 22h13}

Muito interessante a visão do filme com o Toddy sendo a consciência de Leonard, como uma forma de ao mesmo tempo fugir e voltar a realidade. Porém eu acho que mais do que querer esconder o seu verdadeiro eu, a história mostra que Leonard não sabe quem realmente é. Todos os fatos apresentados no filme evidenciam que não é possível concluir que nenhuma informação apresentada seja totalmente verdadeira ou falsa. Isso ocorre pelo fato do filme ser narrado do ponto de vista da mente de Leonard.

No quadro 8, E2 insere um fato ainda não mencionado destacando convergência com as ideias de E3.

\section{Quadro 8. Interação do estudante - E2}

E2 - 11 abr. 2014, às $22 \mathrm{~h} 37$

uma cena legal q corrobora sua idéia dele se esconder é qdo ele queima as fotos para não se lembrar daqueles fatos.

A força enunciativa dos argumentos de E2 reproduzem uma certa legitimidade das circunstâncias expostas, que vão ao encontro das impressões de E4, reveladas no quadro 9.

\section{Quadro 9. Interação do estudante - E4}

\section{E4 - 12 abr. 2014, às 23h34}

legal suas conclusões, mas não acho que ele se colocou nesse mundo de mentiras, mas foi graças à manipulação que ele sofra que isso aconteceu. E sobre a memória eu concordo que ele não confiava nelas, e essa é uma sacada legal, pois até chega a parecer que não ter memória pra confiar torna sua busca menos viesada (o que, dependendo do ponto de vista, até pode ser verdade).

A interação entre os sujeitos discursivos no espaço comunicacional fornece subsídios necessários para que o enunciado se torne consistente ao se relacionar com os outros e crie uma amálgama de valores sintáticos e semânticos na projeção no diálogo. Em cada enunciado é possível depreender intenções, interpretar sentidos e avaliar posturas de ordem social e ideológica impressas nas verbalizações do locutor, que conduz os delineamentos tangíveis no discurso [Bakhtin, 2011].

Diante disso, verifica-se em E3 a explanação de uma imagem expressa por um encadeamento lógico de enunciados que se edifica na correlação de valores oriundos da personagem Leonard. A harmonia enunciativa confere um sentido e provoca outras construções enunciativas de convergência e de divergência pautadas em novos olhares e novas considerações a respeito da mesma ideia, como visto na abordagem de E2 e E4.

E2 admite a percepção inicial de E3 acerca da consciência, porém rebate as demais opiniões deste com base em analogias que conferem o ponto de vista da protagonista a partir de atitudes sobre um foco delimitado. E4, por sua vez, registra suas impressões sobre o olhar de E3 atribuindo juízo favorável em relação às memórias de Leonard e desfavorável acerca do entorno de mentiras em que este se insere, assim constrói enunciados que se sustentam com base nas recentes interpretações.

Para apoiar a sondagem de atuação enunciativa dos participantes no cenário discutido, cabe explanar a visão bakhtiniana de que "todo enunciado é um elo na cadeia da comunicação discursiva, é a posição ativa do falante nesse ou naquele campo do objeto e do 
CBIE-LACLO 2015

Anais do XXI Workshop de Informática na Escola (WIE 2015)

sentido". A estrutura que esboça a formação enunciativa é estabelecida, antes de tudo, pelas "ideias do sujeito do discurso centradas no objeto e no sentido" [Bakhtin, 2011, p. 289].

O tratamento sobre produção de sentido denota premissas que vão além das significações reproduzidas pelos enunciados, utiliza-se das configurações linguísticas que assumem características dialógicas na relação de contextos históricos, sociais e ideológicos concebidos entre os membros que integram uma dinâmica interativa.

As atribuições enunciativas reproduzidas nos discursos dos participantes conferem à linguagem papel dialógico de interação social. Por conseguinte evidenciam-se as situações de produção dos enunciados que são efetivamente gerenciadoras de sentido.

\section{Considerações finais}

A linguagem, apesar de assumir diferentes formas para diferentes atores, apresentou variados sentidos textuais a partir das relações dialógicas, polifônicas, heterogêneas e discursivas, que tiveram como base as condições de produção dos enunciados.

Pudemos notar os efeitos dialógicos quando um enunciado se constituía a partir de outrem, produzindo contextos pertinentes e significativos. Com isso, as correlações textuais admitidas em determinada situação ativaram uma gama de interpretações possíveis e instauraram um jogo de apreensão, parecer e reconhecimento sociocognitivo acarretando sentidos ao entrelaçar opiniões distintas.

A alteridade entre os interlocutores promoveu negociações que se estabeleceram no cenário de troca de experiências resultantes da interatuação dinâmica dos alunos. Assim, as relações dialógicas necessárias para suprir os propósitos didáticos foram conduzidas por atitudes de incentivo, reflexão, problematização e respostas.

No decorrer das ações didáticas observamos que não bastou ao ouvinte apenas interpretar os sinais expressos pelo locutor, foi preciso que houvesse uma relação profícua entre os fundamentos textuais e de ordem contextual a fim de que fosse possível interpretar, depreender e assimilar as noções conjuntas para determinada situação ou circunstância. Ressaltamos, para tanto, que no domínio do texto, algumas informações foram registradas por meio de inferências, dessa forma, o reconhecimento desse aspecto constituiu-se como característica importante para uma outra produção de sentido.

Em correspondência à interação didática assíncrona, verificamos que houve um revestimento da linguagem verbal e enunciativa responsável pela ampla flexibilidade discursiva do participante, ao conferir imediatismo ou não de respostas dos contextos apreendidos. Como não se realizou a interação face a face, a construção da aprendizagem pode acontecer de acordo com a cadência específica de cada estudante no que se referiu à leitura, assimilação de dados, analogias, reflexões, comentários, questionamentos e propostas de soluções.

Os levantamentos que expusemos nessa análise permitiram reiterar a hipótese de que as constituições dialógicas e enunciativas, desveladas na atividade didática em mídia social pela internet, estimularam a produção de sentido conferida em ações expressas na interação assíncrona e dinâmica dos discentes. Além disso, nos possibilitou evidenciar as 
mídias sociais, especificamente, o Facebook, como importante ferramenta para a área de Educação, à medida que tal instrumento possa ser visto como recurso que ultrapasse os propósitos socioculturais de interação social, evidenciando, dessa maneira, as contribuições tecnológicas para alternativas viáveis no processo de ensino-aprendizagem.

\section{Referências}

Bakhtin, M. M. (2011) Estética da criação verbal. Trad. Paulo Bezerra. 6. ed. São Paulo: WMF Martins Fontes.

. (2009) Marxismo e filosofia da linguagem: problemas fundamentais do método sociológico da linguagem. Trad. Michel Lahud e Yara Frateschi Vieira. 13. ed. São Paulo: Hucitec. (Linguagem e Cultura, 3).

Castells, Manuel. (1999) A sociedade em rede. Trad. Roneide Venancio Majer. 6. ed. São Paulo: Paz e Terra. (A era da informação: economia, sociedade e cultura; v.1).

Cortês, Norma. "Amnésia, o tempo como construção". Disponível em: http://www.espacoacademico.com.br/022/22ccortes.htm. Acesso em: 15 abr. 2014.

Dotta, Sílvia. (2009) Aprendizagem dialógica em serviços de tutoria pela internet: Estudo de caso de uma tutora em formação em uma disciplina a distância. São Paulo: Feusp. (Tese de doutorado).

. Uso de uma Mídia Social como Ambiente Virtual de Aprendizagem. Anais do

XXII SBIE - XVII WIE, Aracaju, 2011. Disponível em: http://www.brie.org/pub/index.php/sbie/article/view/1623/1388. Acesso em: 29 abr. 2015.

Dotta, Sílvia; Giordan, Marcelo. (2006) Estudo das Interações Discursivas mediadas por um serviço de tutoria pela internet. Anais do $13^{\circ}$ Encontro Nacional de Didática e Prática de Ensino. Recife, XIII Endipe/UFPE, 23 a 26 abr. Disponível em: http://www.lapeq.fe.usp.br/ silviadotta/textos/artigo_silviadotta_semana_educacao.pdf. Acesso em: 27 abr. 2015.

(2014) Estratégias para Condução do Diálogo a Distância. Revista Brasileira de Informática na Educação. Volume 22, Número 2, 2014. Disponível em: http://www.brie.org/pub/index.php/rbie/article/view/2419. Acesso em: 29 abr. 2015.

Fiorin, José Luiz.(2008) Introdução ao pensamento de Bakhtin. São Paulo: Ática.

Freire, Paulo. (1987) Pedagogia do oprimido. 17. ed. Rio de Janeiro: Paz e Terra. (O mundo, hoje, v. 21).

Recuero, Raquel. (2009) Redes sociais na internet. Porto Alegre: Sulina. (Coleção Cibercultura). 